\title{
Helium Radiofrequency Atomization and Excitation Source (He-RFAES) for Simultaneous Direct Determination of Trace Elements in Solid Samples
}

\author{
Hirofumi InOUe, Masahito FukUda, Kuniyuki Kitagawa*, and Shin Tsuge \\ Department of Applied Chemistry, School of Engineering, Nagoya University, \\ Furo-cho, Chikusa-ku, Nagoya 464-01, Japan \\ *Present Address: Research Center for Advanced Energy Conversion, Nagoya University, \\ Furo-cho, Chikusa-ku, Nagoya 464-01, Japan
}

(Received September 6, 1996)

井上博文·福田政化·北川邦行*·柘植 新

名古屋大学応用化学科 名古屋市千種区不老町 (

*現住所 : 名古屋大学高温エネルギー変換研究センター 名古屋市千種区不老町（テ464-01）

(1996年 9 月 6 日 受理)

\begin{abstract}
Synopsis
A radiofrequency Ar discharge lamp with a hot electrode, radiofrequency atomization/excitation source $(R$ $F A E S$ ), has been developed for direct determinations of trace elements in solid samples by atomic emission spectrometry ${ }^{1}$ ) In this work, a He RFAES was developed to attain higher excitation temperatures. Among the advantages of the RFAES is the capability of direct simultaneous determinations of elements including halogens in solid samples. At the center of a stainless-steel cylinder, a tantalum cup loaded with a small size sample (5-10 $\mu l$ or $\mathrm{mg}$ ) was located and served as a discharge electrode. When an r.f. He plasma was formed between the tantalum cup and the grounded cylindrical enclosure under a reduced pressure, the cup was concurrently heated to a high temperature, owing to the r.f. power dissipation. As a consequence, the sample loaded in the cup was atomized and excited in the He plasma. Compared with graphite, tantalum was effective to attain higher cup temperatures $\left(>2300^{\circ} \mathrm{C}\right)$. Basic characteristics and analytical performance were evaluated with standard solutions. The RFAES was successfully applied to simultaneous direct determinations of elements including $\mathrm{Cl}$ in a NIST standard reference material of biological matrix, SRM 1571 Orchard Leaves.
\end{abstract}

Keywords: He discharge plasma, direct atomization/excitation, simultaneous determinations, solid sampling, atomic emission spectrometry

\section{Introduction}

Atomic emission spectrometry (AES) has an advantage of simultaneous multielement determinations, as exemplified by inductively coupled plasma atomic emission spectrometry (ICP-AES) applied to solution analyses. The conventional procedures of solid analyses by ICP-AES requires acid digestion or alkali fusion. However, such chemical pretreatments are time-consuming and accompanied by a risk of analyte contamination from the reagents used and environment. With this regard, it is important to estab- lish a method of direct analysis of solid samples. Several techniques of solid sampling such as laser ablation $^{2,3)}$, slurry nebulization ${ }^{4,5)}$ and direct insertion ${ }^{6)}$ have been proposed for ICP-AES. Furnace atomic non-thermal spectroscopy (FANES) ${ }^{7)}$ and furnace atomic plasma excitation spectroscopy (FAPES) ${ }^{8)}$ are among promising tecniques for micro solid sampling. Graphite cup capacitively coupled microwave plasma atomic emission spectroscopy ${ }^{9)}$ also has been applied to solid sampling.

Recently, a radio frequency Ar discharge lamp with a hot electrode, a radiofrequency atomization and excitation source (RFAES) ${ }^{1)}$ has been devel- 
oped for direct solid analysis by AES. In this study a He RFAES was developed to attain higher excitation of elements, including halogens. Tantalum with low emissivity was employed for the material of the sample cup of a He-RFAES in order to attain high temperatures above $2300^{\circ} \mathrm{C}$. The analytical performance of the He-RFAES was evaluated for direct multielement determinations of a biological standard reference sample, NIST SRM 1571 Orchard Leaves.

\section{Experimental}

\subsection{Instrumentation}

The schematic diagram of the He-RFAES system developed for this study is shown in Fig. 1 and the components are listed in Table 1 . The other instruments used are basically the same as those used in the previous work ${ }^{1)}$. A polychromator and a monochromator are located on both sides of the HeRFAES. The polychromator is used to measure simultaneously the analytical lines listed in Table 2, while the monochromator is used to observe a line which is not measurable by the polychromator (the $\mathrm{Cl}$ line in this experiment, see also Table 2). The polychromator was mounted vertically on an optical bench. Consequently, the entrance slit of the polychromator was horizontal.

The stainless steel enclosure (8) of the HeRFAES constructed for this work is basically the same as that used in previous work ${ }^{1)}$ except that its thermal durability is improved by water-cooling. In order to concentrate the discharge plasma around the sample cup, the center electrode is covered with an $\mathrm{Si}_{3} \mathrm{~N}_{4}$ insulator tube of $10 \mathrm{~mm}$ o.d., $6 \mathrm{~mm}$ i.d. and $42 \mathrm{~mm}$ in length (6). For the previous RFAES, an

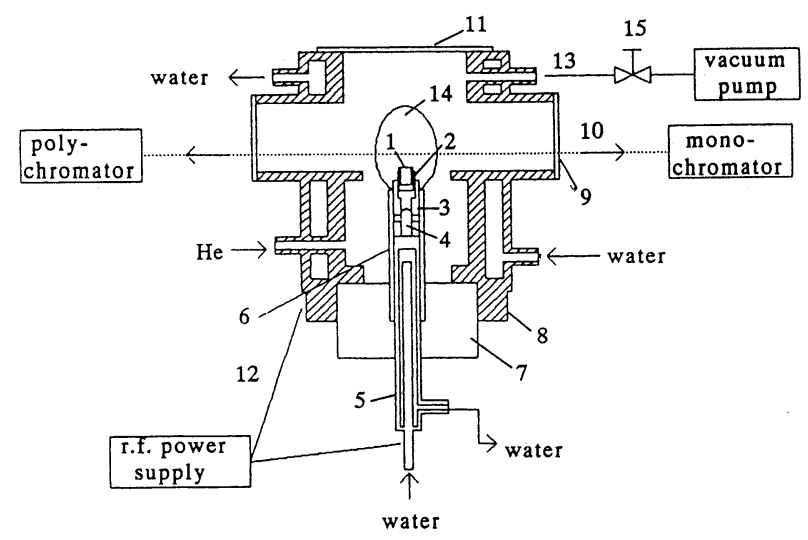

Fig. 1 Schematic diagram of RFAES.

(1), Ta sample cup; (2), graphite support cup; (3), $\mathrm{SiC}$ insulation cup; (4), graphite screw; (S), stainless-steel center electrode; (6), $\mathrm{Si}_{3} \mathrm{~N}_{4}$ tube; (7), Macor base; (8), cylindrical stainless-steel enclosure (grounded); (9), quartz windows; (10), to spectrometer; (11), quartz lid; (12), to r.f. matching box; (13), to vacuum pump; and (14), r.f. plasma; (15), pressure-control valve.
Table 1 Instrumentation

\begin{tabular}{ll}
\hline Matching box & $\begin{array}{l}\text { Tokyo HyPower HC-2000 } \\
50 \Omega \text { input }(2 \mathrm{~kW} \text { max.) } \\
10-50 \Omega \text { output }\end{array}$ \\
Polychromator & $\begin{array}{l}\text { Nippon Jarrel Ash D-70 with a grating of } \\
2400 \text { grooves } / \mathrm{mm} \text { and slits of } 25 \mu \mathrm{m} \text { in } \\
\text { width } \\
\text { (spectral bandwidth }=0.02 \mathrm{~nm})\end{array}$ \\
Monochromator & $\begin{array}{l}\text { Nippon Jarrel Ash JE- } 50 \mathrm{E} \text { with a grating of } \\
1200 \text { grooves } / \mathrm{mm} \text { and slits of } 25 \mu \mathrm{m} \text { in }\end{array}$ \\
& $\begin{array}{l}\text { width } \\
\text { (spectral bandwidth }=0.04 \mathrm{~nm})\end{array}$ \\
Hetector & $\begin{array}{l}\text { Hamamatsu Photonics R106 PMT } \times 12 \text { for } \\
\text { polychromator and R666 PMT for } \\
\text { monochromator. All of them are installed } \\
\text { with Current-to-voltage converters (OP-27 } \\
\text { operational amplifier) }\end{array}$ \\
\hline
\end{tabular}

The other instruments are the same as those used in previous work $^{1)}$.

Table 2 Analytical wavelengths

\begin{tabular}{lcc}
\hline Line & Wavelength/nm & Excitation energy/eV \\
\hline $\mathrm{Zn}(\mathrm{I})$ & 213.856 & 5.80 \\
$\mathrm{In}(\mathrm{I})$ & 451.132 & 2.75 \\
$\mathrm{Cr}(\mathrm{I})$ & 425.435 & 2.91 \\
$\mathrm{~Pb}(\mathrm{I})$ & 283.306 & 4.38 \\
$\mathrm{Fe}(\mathrm{I})$ & 300.095 & 4.13 \\
$\mathrm{Cu}(\mathrm{I})$ & 324.754 & 3.82 \\
$\mathrm{Be}(\mathrm{II})$ & 313.107 & 3.96 \\
$\mathrm{Mn}(\mathrm{II})$ & 257.610 & 4.81 \\
$\mathrm{Cd}(\mathrm{I})$ & 228.802 & 5.42 \\
$\mathrm{Cl}(\mathrm{II})$ & 479.454 & 15.96 \\
\hline
\end{tabular}

alumina tube was used for the insulator, which was of less thermal tenacity. The center electrode is also water-cooled in order to protect the $\mathrm{Si}_{3} \mathrm{~N}_{4}$ tube from thermal shocks. At the top of the center electrode, an $\mathrm{SiC}$ insulation cup of $5 \mathrm{~mm}$ i.d., $6.5 \mathrm{~mm}$ o.d. and $8 \mathrm{~mm}$ in height (3), a graphite support cup of 3.7 $\mathrm{mm}$ i.d. and $5 \mathrm{~mm}$ o.d., $8 \mathrm{~mm}$ in height and $3 \mathrm{~mm}$ in depth (2), a tantalum sample cup of $2.5 \mathrm{~mm}$ i.d. and $3.7 \mathrm{~mm}$ o.d., $4 \mathrm{~mm}$ in height and $3 \mathrm{~mm}$ in depth (1) are piled up in this order. For a comparison, a graphite sample cup of $3.7 \mathrm{~mm}$ i.d. and $5 \mathrm{~mm}$ o.d., $10 \mathrm{~mm}$ in height and $5 \mathrm{~mm}$ in depth was also tested. All of these cups are laboratory-made. In order to avoid contamination, a diamond-coated drill was used for preparing the cups.

Radiofrequency power is conducted to the Ta sample cup through a graphite screw of $3 \mathrm{~mm}$ diameter and $12 \mathrm{~mm}$ in length (4) connecting the stainlesssteel center electrode and the graphite support cup. The Ta sample cup also serves as an electrode which is effectively heated above $2300^{\circ} \mathrm{C}$, as follows. When r.f. power $(13.56 \mathrm{MHz})$ is supplied to the center electrode, a He plasma discharge is formed between the Ta cup electrode and the grounded cylindrical enclosure which also serves as a counter electrode. Subsequently, the Ta cup is heated by the plasma 
formed and r.f. power dissipation. As the result, the sample in the Ta cup is atomized and immediately excited in the surrounding $\mathrm{He}$ plasma. The He flow rate was adjusted with a valve set in the tubing from a He cylinder to the RFAES, and the He pressure in the RFAES was adjusted with a valve connected to the vacuum line (13).

The Ta cup-RFAES operated with an impedance of $2 \Omega$ in resistance and $126 \Omega$ in reactance at $500 \mathrm{~W}$. The impedance was estimated from the tune and load scales of a matching box (Tokyo Hypower HC2000). The sample cup temperature was measured by a digital optical pyrometer (Minolta TR-630) through the quartz lid (11). The emissivity correction was made using $\varepsilon=1$ for a graphite cup and 0.4 for a Ta cup. The quartz windows (9) on both sides of the cylindrical enclosure are used to observe the analytical emission by the polychromator and the monochromator, respectively. The emission signals were processed for displaying the peak profiles and calculating peak area by a microcomputer (NEC PC-9801 UF) with an analog-to-digital converter interface. The programs used for the microcomputer were written in a $\mathrm{C}$ language.

\subsection{Standard Solutions}

Stock standard solutions of $\mathrm{Cr}, \mathrm{Fe}, \mathrm{Cu}$ and $\mathrm{Mn}$ were prepared by dissolving pure metals ( $>99.9 \%$ ) in a $2 \mathrm{M} \mathrm{HNO}_{3}$ solution and adjusting the acidity to 1.0 M. Stock standard solutions of $\mathrm{Zn}, \mathrm{In}, \mathrm{Pb}, \mathrm{Be}, \mathrm{Cd}$ and $\mathrm{Mg}$ were those commercially available (Wako Pure Chemical). A stock standard solution of $\mathrm{Cl}$ was prepared by dissolving ammonium chloride in distilled-deionized water. All the reagents used were of analytical grade. The standard test solutions were prepared by mixing the stock solutions and diluting with distilled-deionized water just before use. Graphite of spectroscopic grade (Hitachi) was used for the electrode material. Carbon tetrachloride vapor was mixed in the $\mathrm{He}$ gas for the wavelength adjust of the line $\mathrm{Cl}$. The purities of $\mathrm{He}$ and $\mathrm{Ar}$ were more than $99.995 \%$ and $99.999 \%$, respectively.

\subsection{Slurry Preparation}

The standard reference material, NIST SRM 1571 Orchard Leaves was used as a biological solid sample. Slurry was prepared by dispersing $100.0 \mathrm{mg}$ of the Orchard Leaves in $1.0 \mathrm{ml}$ of distilled-deionized water containing $0.04 \%$ Triton- $\mathrm{X}$ as a dispersing reagent. A mechanical vibrator (Yamato Kagaku) was used for shaking a sample container $(1 \mathrm{~m} l$ in volume). The slurry concentration was $0.1 \mathrm{mg} / 1 \mu \mathrm{l}$ when taken into a micropipette. As a matrix modifier, $0.5 \mathrm{mg}$ of $\mathrm{Pd}\left(\mathrm{as} \mathrm{Pd}\left(\mathrm{NO}_{3}\right)_{2}\right)$, and $0.5 \mathrm{mg}$ of $\mathrm{Mg}$ (as $\left.\mathrm{Mg}\left(\mathrm{NO}_{3}\right)_{2}\right)$ were added to the slurry. The appearance of analyte emission was delayed in the presence of $\mathrm{Pd}^{10)}$, resulting in avoidance of overlapping of analyte and molecular emission peaks. In addition, the presence of $\mathrm{Mg}$ suppressed the analyte loss on the charring step ${ }^{1}$.

\subsection{Measurement procedures}

Ten $\mu l$ of a standard solution was deposited into the sample cup (Ta or graphite) with a micropipette. The air in the RFAES was evacuated for ca. $3 \mathrm{~min}$, when the sample was dried. Subsequently, He was introduced as a plasma gas under a pressure adjusted to $2.6-8.0 \mathrm{kPa}$. Then, an r.f. power of up to $600 \mathrm{~W}$ was supplied and an r.f. plasma was formed. Consequently, the sample cup was heated to atomize and excite the analyte.

A separate chamber, which was basically the same as that constructed in previous work ${ }^{1)}$, was used to char biological sample matrices. The charring chamber incorporates a graphite cup supported by two graphite rods. While the container was being agitated by the mechanical vibrator, $10 \mu l$ of the resulting slurry was taken into the Ta sample cup by a micro pipette. The Ta cup was mounted in the graphite cup in the charring chamber, using ceramic tweezers. By passing $\mathrm{AC}$ current, the graphite cup was heated resistively in Ar atmosphere. Thus, the sample in the Ta cup was dried at $120^{\circ} \mathrm{C}$ for $3 \mathrm{~min}$ and then charred at $600^{\circ} \mathrm{C}$ for $60 \mathrm{sec}$. After covered with a hollow lid, the Ta sample cup was transferred into the support graphite cup of the He-RFAES.

\section{Results and Discussion}

\subsection{Basic characteristics of the He r.f. dis- charge}

For a comparison, spectral intensities of atomic and ionic lines, obtained with $\mathrm{He}$ and Ar discharges are listed in Table 3. The background emission intensities were almost the same for both plasmas. It is noted that the emission intensities of the ion lines are significantly enhanced. This suggests that the ioniza-

Table 3 Comparison of emission intensities for $\mathrm{He}$ and $\mathrm{Ar}$ plasmas

\begin{tabular}{lcccc}
\hline \multirow{2}{*}{ Line } & Wavelength $(\mathrm{nm})$ & \multicolumn{3}{c}{ Relative intensities* } \\
\cline { 3 - 5 } & & $\mathrm{Ar}$ & $\mathrm{He}$ & $\mathrm{He} / \mathrm{Ar}$ \\
\hline $\mathrm{Zn}(\mathrm{I})$ & 213.856 & 1.0 & 1.8 & 1.8 \\
$\mathrm{Cu}(\mathrm{I})$ & 324.754 & 1.0 & 2.2 & 2.2 \\
$\mathrm{Mg}(\mathrm{I})$ & 285.213 & 1.0 & 0.6 & 0.6 \\
$\mathrm{Mg}(\mathrm{II})$ & 279.553 & 0.4 & 5.4 & 14 \\
$\mathrm{Mn}(\mathrm{I})$ & 279.482 & 1.0 & 4.0 & 4.0 \\
$\mathrm{Mn}(\mathrm{I})$ & 403.076 & 5.9 & 3.2 & 0.5 \\
$\mathrm{Mn}(\mathrm{II})$ & 257.610 & 0.7 & 15 & 21 \\
\hline
\end{tabular}

*Peak area. Atomic line intensity was used as the reference. The experimental conditions were as follows: for the He plasma, He flow rate of $1.4 \mathrm{lmin}^{-1}$, discharge pressure of $2.6 \mathrm{kPa}$, r.f. power of $500 \mathrm{~W}$ and for the Ar plasma, Ar flow rate of $0.15 \mathrm{lmin}^{-1}$, pressure of $0.7 \mathrm{kPa}$, r.f. power of $300 \mathrm{~W}$. The difference in the operational conditions, between the $\mathrm{He}$ and Ar plasma were due to the discharge characteristics of each gas. The conditions of the Ar plasma were optimized while those of He plasma were only dischargeable. These experiments were performed with a graphite cup-RFAES. 


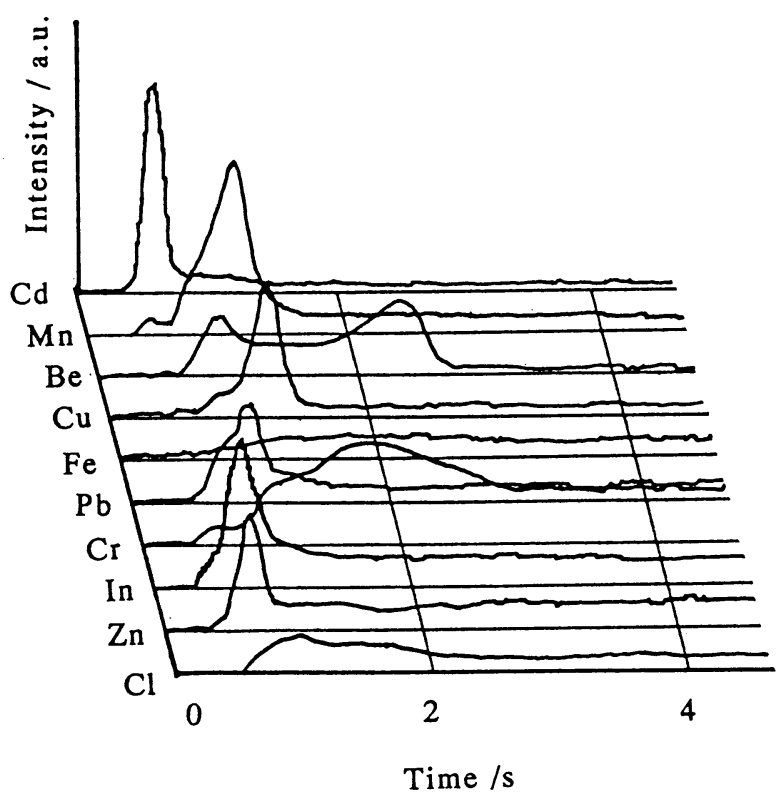

Fig. 2 Typical emission peak profiles for 10 elements in a mixed solution sample. Analyte mass, $100 \mathrm{ng}(\mathrm{Cr}$, $\mathrm{Fe}, \mathrm{Pb}$ and $\mathrm{In}) ; 10 \mathrm{ng}(\mathrm{Be}, \mathrm{cd}, \mathrm{Zn}, \mathrm{Cu}$ and $\mathrm{Mn}) ; 10$ $\mu \mathrm{g}(\mathrm{Cl})$. The operating conditions are listed in Table 3.

Table 4 Operating conditions of the Ta cup RFAES for standard solution samples

\begin{tabular}{ll}
\hline r.f. power & $400 \mathrm{~W}$ \\
He pressure & $8.0 \mathrm{kPa}$ \\
He flow rate & $0.75 \mathrm{lmin}^{-1}$ (NTP) \\
Observation height & $0 \leqq \mathrm{~h} \leqq 25 \mu \mathrm{m}$ \\
Sample volume & $10 \mu l$ \\
Cup temperature & ca. $2200^{\circ} \mathrm{C}$ \\
\hline
\end{tabular}

tion is promoted in the He plasma ${ }^{12)}$. Consequently, the intensities of atomic lines are lowered, except for the $\mathrm{Zn}$ line of a high excitation energy.

Typical emission peaks obtained with a Ta cup under the optimum conditions (Table 4) are shown in Fig. 2. The emissions are completed for all the elements within $4 \mathrm{~s}$ after the discharge was initiated. This figure indicates the capability of He-RFAES to detect multielements simultaneously, together with $\mathrm{Cl}$.

\subsection{Cup temperature}

Figure 3 shows the dependence of the cup temperature on the applied r.f. power. It indicates that at the same r.f. power, the temperatures obtained with the Ta cup are higher by ca. $600^{\circ} \mathrm{C}$ than those obtained with the graphite cup. The discrepancy is mainly attributable to the difference in emissivity between $\mathrm{Ta}$ $(\varepsilon \fallingdotseq 0.4)$ and graphite $(\varepsilon \fallingdotseq 1)$. To confirm this, the radiative heat loss was estimated from a temperature rise of the cooling water flowing in the cylindrical enclosure of the He-RFAES. At an r.f. power of 500

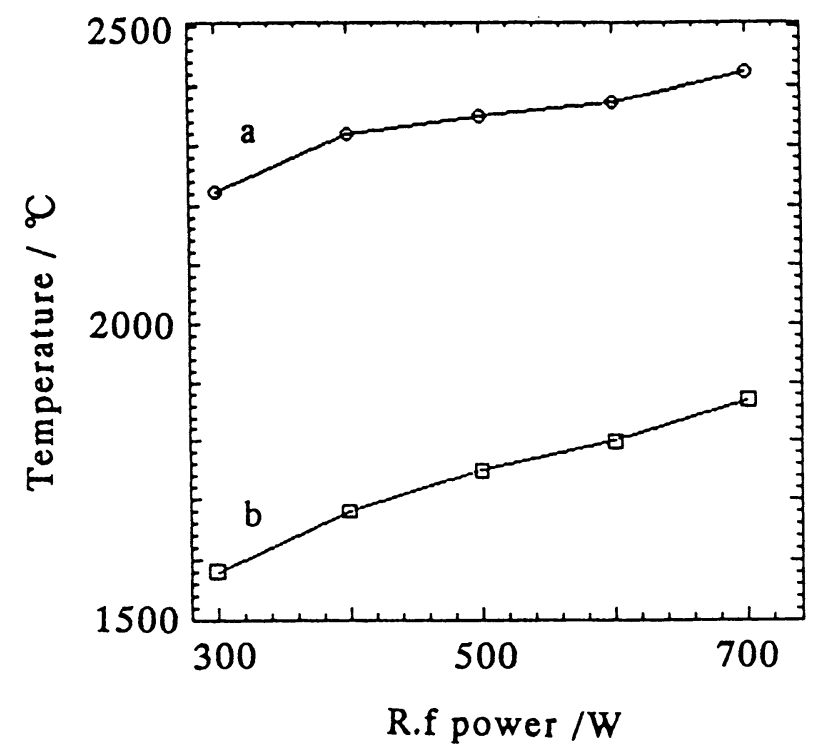

Fig. 3 Dependence of sample cup temperature on r.f. power.
(a), Ta cup (emissivity $\fallingdotseq 0.4$ )
(b), graphite cup (emissivity $\fallingdotseq 1.0$ )

$\mathrm{W}$, the heat loss were 67 and $98 \mathrm{~W}$ for the Ta and graphite cups, respectively. Thus, radiative heat loss is significantly decreased for the Ta cup with low emissivity.

Tantalum was not only effective to attain high temperatures but also had following advantages over graphite. (1) the sputtering rate by the plasma was much less, leading to a longer lifetime (ca. 3 fold) of the sample cup and less significant contamination inside the enclosure. (2) stable plasma was attainable at a higher pressure of $8.0 \mathrm{kPa}$. Consequently, the emission intensity became higher because of increased plasma density. (3) The rise time of the cup temperature became shorter: ca. $0.2 \mathrm{sec}$. and ca. 0.7 sec. for the $\mathrm{Ta}$ and graphite cups to reach an equilibrium temperature, respectively.

\subsection{Flow rate and pressure}

Figure 4 shows the dependencies of the spectral intensities for various atomic lines on the He flow rate under a constant pressure (a) and on the He pressure at a constant flow rate (b). The experiments were made with the mixture solution of 9 elements and the results for $\mathrm{Cd}, \mathrm{Mn}$ and $\mathrm{Cu}$ are shown. These 3 elements were selected from a view point of the difference in the magnitude of excitation energy (see Table 2). However, no obvious differences are recognized from Fig. 4 (a). A maximum emission intensity is found at $0.75 \mathrm{lmin}^{-1}$ for all the elements. The emission intensity decreases at higher flow rates. This is probably because the residence time of analyte vapors in the plasma becomes shorter. The cause of the weaker emission intensities at lower flow rates may lie in the increase in the concentration of air leaking from the atmosphere into the RFAES chamber. Diatomic molecules, $\mathrm{O}_{2}$ and $\mathrm{N}_{2}$ absorbs the plas- 


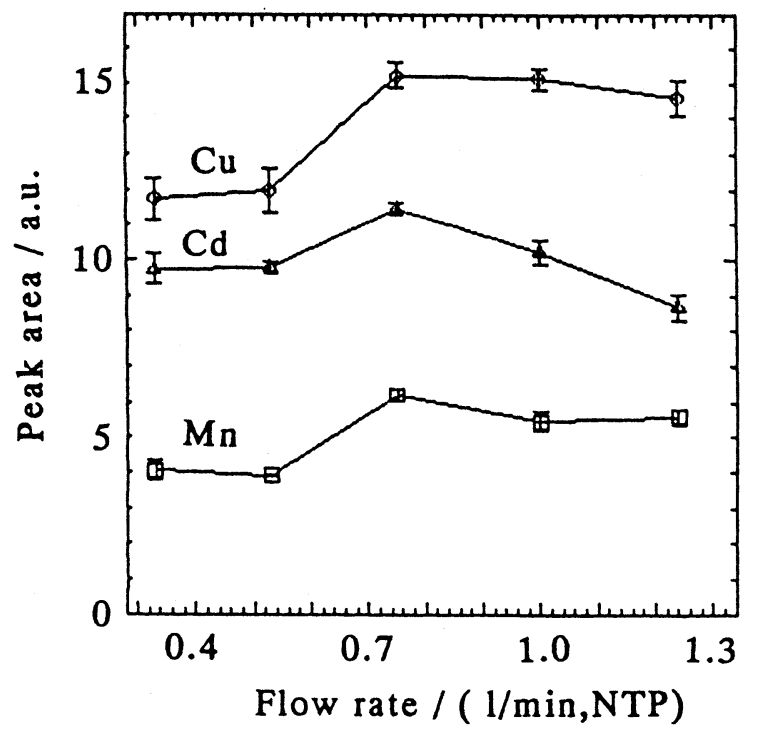

(a)

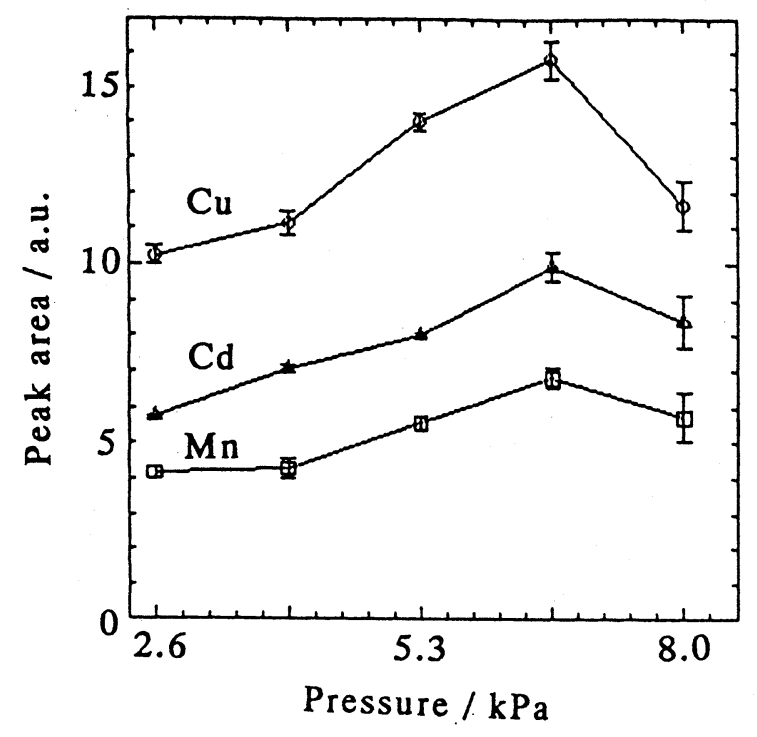

(b)

Fig. 4 (a) Relation between He flow rate and emission intensity at various atomic lines.

He pressure, $5.3 \mathrm{kPa}$; observation height $0 \leqq \mathrm{~h} \leqq 25$ $\mu \mathrm{m}$; sample cup, graphite. (b) Relation between $\mathrm{He}$ pressure and emission intensity. He flow rate 0.75 $l \mathrm{~min}^{-1}$ (NTP); observation height $0 \leqq \mathrm{~h} \leqq 25 \mu \mathrm{m}$; sample cup, graphite.

ma energy as their vibrational/rotational energy. Fig. 4(b) shows a maximum emission intensity under a pressure of $6.7 \mathrm{kPa}$. However, the relative standard deviation is relatively large under this condition because of plasma instability. On the other hand, the intensity is weaker under lower pressures. This is probably due to the lower plasma density. Figs. 4(a) and (b) indicate that a He flow rate of $0.75 \mathrm{lmin}^{-1}$ and a He pressure of $5.3 \mathrm{kPa}$ are the optimum conditions for the graphite cup-RFAES. The optimum conditions for the Ta cup-RFAES were found to be only

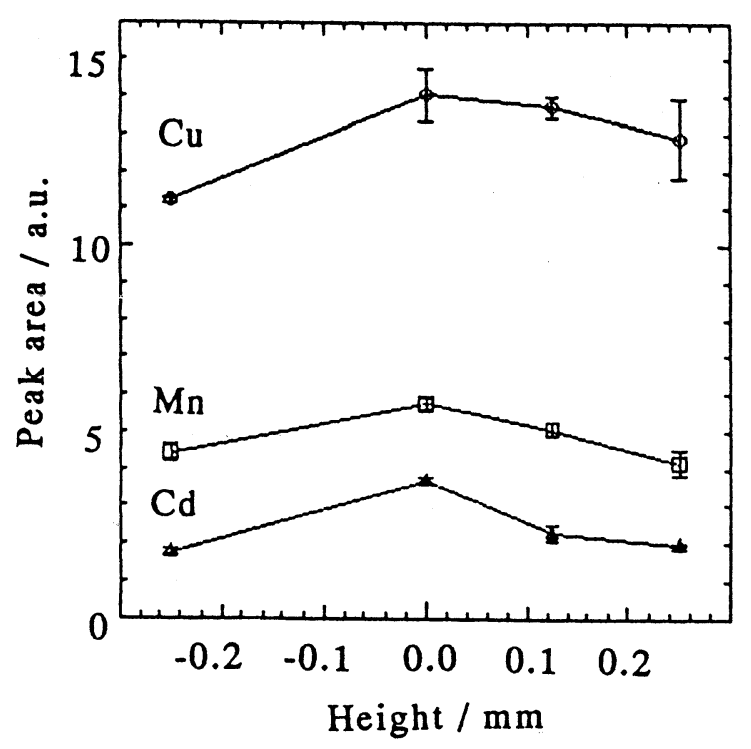

(a)

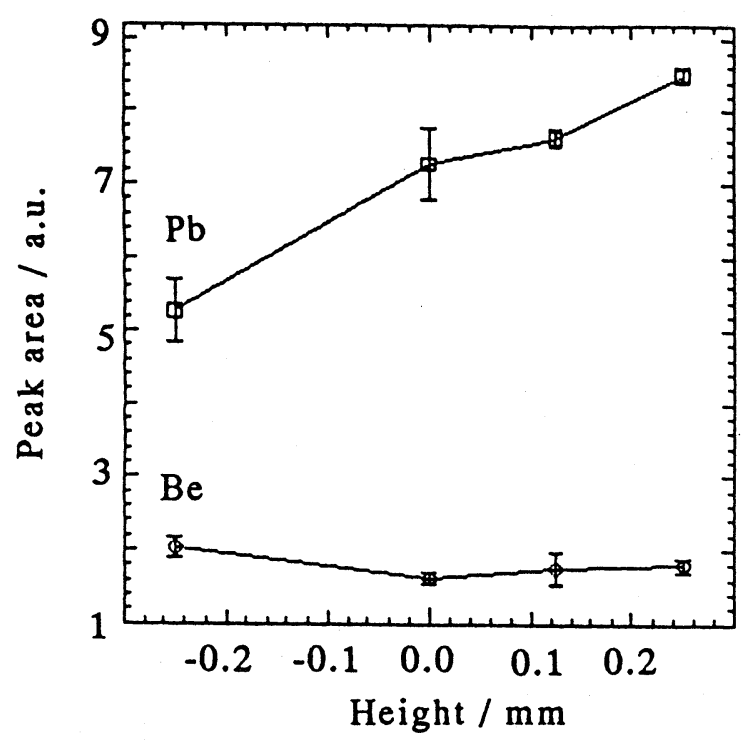

(b)

Fig. 5 Dependence of emission intensity on observation height. He flow rate, $0.75 \mathrm{lmin}^{-1}$ (NTP); He pressure, $5.3 \mathrm{kPa}$.

slightly different from those for the graphite cupRFAES.

\subsection{Observation height}

The variation in emission intensity as a function of the observation height is shown in Fig. 5. By means of a $\mathrm{He}-\mathrm{Ne}$ laser, the observation height of $0.0 \mathrm{~mm}$ was determined as the top end of a sample cup. The positive and negative signs indicate above and below the cup top, respectively. Except for $\mathrm{Pb}$ and Be were obtained almost the same results that the spectral emission is most intensive immediately above the cup top (Fig. 5(a)). Therefore, the observation height of $0 \leqq h \leqq 25 \mu \mathrm{m}$ above the cup top was employed for the multielement determinations, where 
$25 \mu \mathrm{m}$ is the width of the entrance slit of the polychromator. The causes of the exceptional results for $\mathrm{Pb}$ and $\mathrm{Be}$ (Fig. 5(b)) are not clear.

\subsection{Calibration and detection limits}

The calibration curves obtained with the Ta sample cup are shown in Fig. 6. The experiments were carried out with the mixture solution of 10 elements under the conditions as listed in Table 4 . The relative standard deviations were within 5-15\%. The detection limits (D.Ls) observed under the same conditions as for Fig. 6 are listed in Table 5. The D. Ls are calculated on the basis of $\mathrm{S} / \mathrm{N}=3$ where $\mathrm{S}$ is the mean of emission peak areas for the analyte and $\mathrm{N}$ is the relative standard deviation of blank signals in the same integration time as that for analyte emission peak. The measurements were repeated at least 3 times under the same conditions. Fig. 6 indicates the linear dynamic ranges of 2-3 orders which are practically fair for simultaneous multielement determina-

Table 5 Detection limits*

\begin{tabular}{ccc}
\hline \multirow{2}{*}{ Element } & \multicolumn{2}{c}{ D.Ls (ng) } \\
\cline { 2 - 3 } & Ta cup & graphite cup \\
\hline $\mathrm{Zn}$ & 0.45 & 4.7 \\
$\mathrm{In}$ & 0.30 & 22.2 \\
$\mathrm{Cr}$ & 3.1 & 60.6 \\
$\mathrm{~Pb}$ & 18.0 & 17.6 \\
$\mathrm{Fe}$ & 19.5 & 10.5 \\
$\mathrm{Cu}$ & 0.15 & 0.45 \\
$\mathrm{Be}$ & 0.09 & 0.60 \\
$\mathrm{Mn}$ & 0.15 & 3.5 \\
$\mathrm{Cd}$ & 0.15 & 2.1 \\
$\mathrm{Cl}$ & $0.30(\mu \mathrm{g})$ & N.D. \\
\hline
\end{tabular}

${ }^{*}$ Calculated based on $\mathrm{S} / \mathrm{N}=3$ (see text). The wavelengths used are the same as those listed in Table 2.

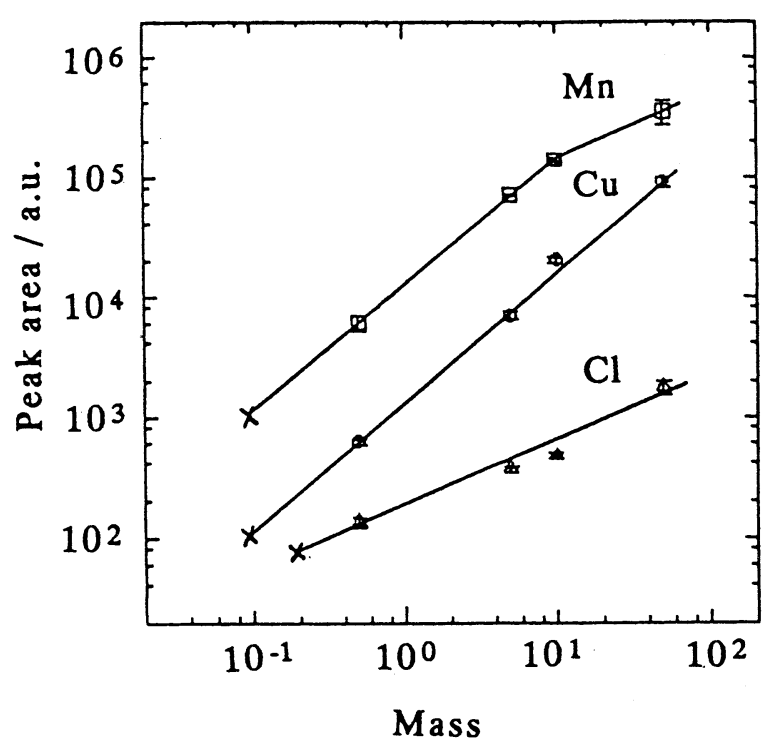

Fig. 6 Calibration curves. Unit of mass, ng for $\mathrm{Cu} ; \mathrm{Mn}, \mu \mathrm{g}$ for $\mathrm{Cl}$. tions except for $\mathrm{Cl}$. The square root dependence of the calibration curve for $\mathrm{Cl}$ is probably caused by recombination of $\mathrm{Cl}$ atoms in the plasma ${ }^{1)}$. In Table 5, D.Ls obtained by the graphite and Ta cup-RFAES under the respectively optimized conditions are listed for a comparison. Except for $\mathrm{Fe}$ and $\mathrm{Pb}$, the D.Ls obtained with the use of the Ta cup are lower. Taking into account their phase diagrams ${ }^{13)}$, it seems that $\mathrm{Fe}$ and $\mathrm{Pb}$ interact with the heated $\mathrm{Ta}$ surface. The D.Ls are not greatly improved, compared to those obtained in previous work ${ }^{1)}$. This suggests that some interelement effects occurring in the simultaneous determinations of multielements increase the DLs. The interelement effects are possibly overcome by raising the plasma energy. Adjusting the photomultiplier tubes in the polychromator to the ion lines which give higher intensity in He plasmas (see Table 3 ) is also promising to obtain lower D.Ls.

3.6 Effect of easily ionizable elements (EIE)

Effects of an easily ionizable element (EIE) in the Ta cup He-RFAES are shown in Fig. 7. Sodium was added as an EIE into the mixture solution of 9 elements. In Fig. 7 (a) are shown the results for the elements which are relatively less significantly affected by the EIE. In Fig. 7 (b) are depicted the results for the elements which suffer enhancing EIE effects at higher $\mathrm{Na}$ concentrations and in Fig. 7 (c), the results for the other elements are shown. The difference among these three types of interference could be attributed to the difference in the excitation mechanisms. In the presence of a large amount of $\mathrm{Na}$, however, delay of appearance time was also observed for the analyte emission peaks. Therefore, the change in vaporization/atomization processes are also involved. The mechanisms associated with the EIE effects seem to be complicated in the simultaneous atomization/excitation of the multielements and are now under investigation.

\subsection{Application to biological solid sample}

In applications of the He/Ta cup-RFAES to a biological solid sample, a serious problem associated with plasma fluctuations was encountered. This is caused by particles of the sample powder, which are forced to rapidly enter the plasma by the expansion of He in the sample cup on firing. Several shapes of lids are tested to suppress this phenomenon. Finally, it was found effective to cover the sample powder in the cup with a Ta hollow lid of $1.5 \mathrm{~mm}$ i.d., $2.5 \mathrm{~mm}$ o.d. $3 \mathrm{~mm}$ in height and $2.2 \mathrm{~mm}$ in depth. The lid has a hole of $1.0 \mathrm{~mm}$ in diameter at the center of the bottom, through which the atomic/molecular vapors evolving from the sample powder enter the plasma. The plasma stabilization by the hollow lid is partly owing to a so-called hollow effect, or condensation of the current density, which is encountered in hollow cathode lamps used for atomic absorption spectrometry (AAS).

The typical peak profiles for NIST SRM 1571 Orchard Leaves, using the hollow lid are shown in Fig. 
(a)

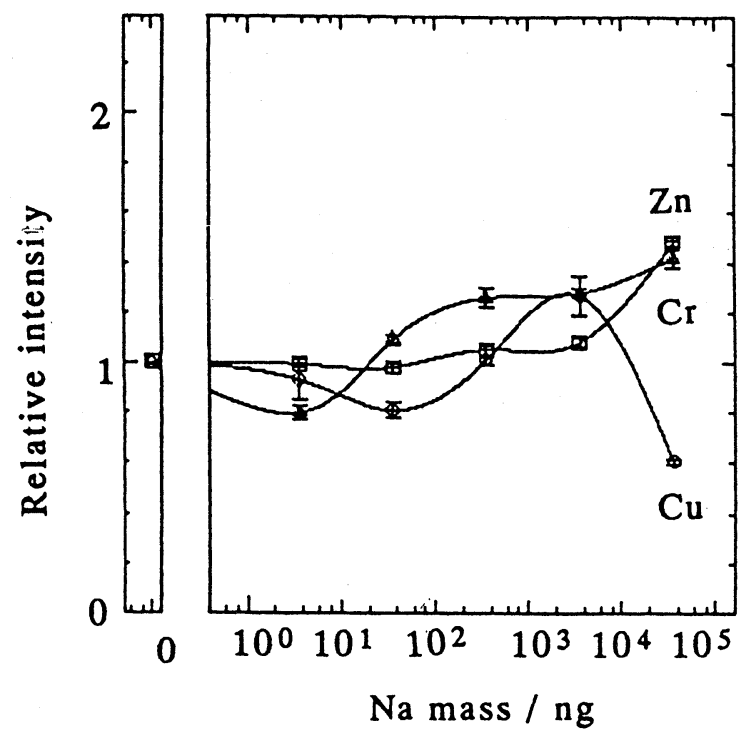

(b)

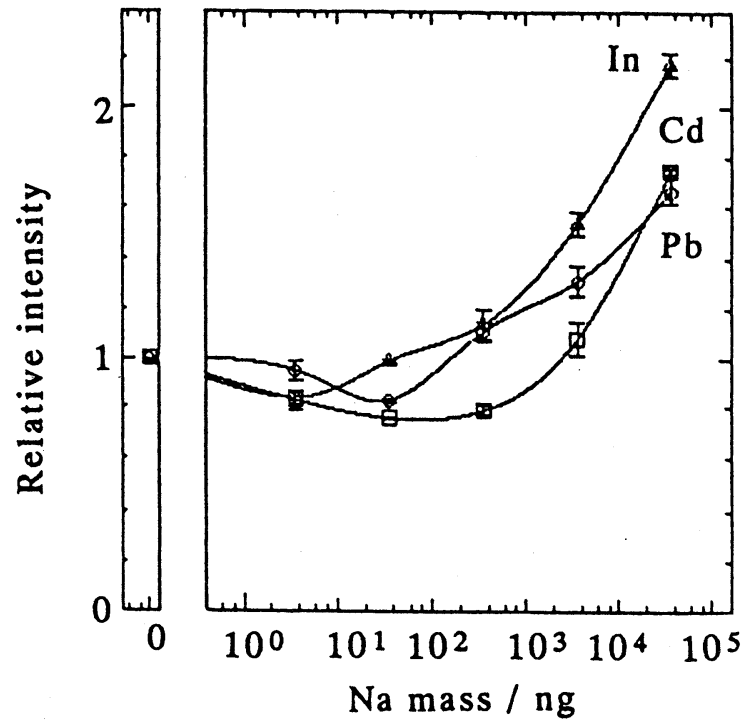

(c)

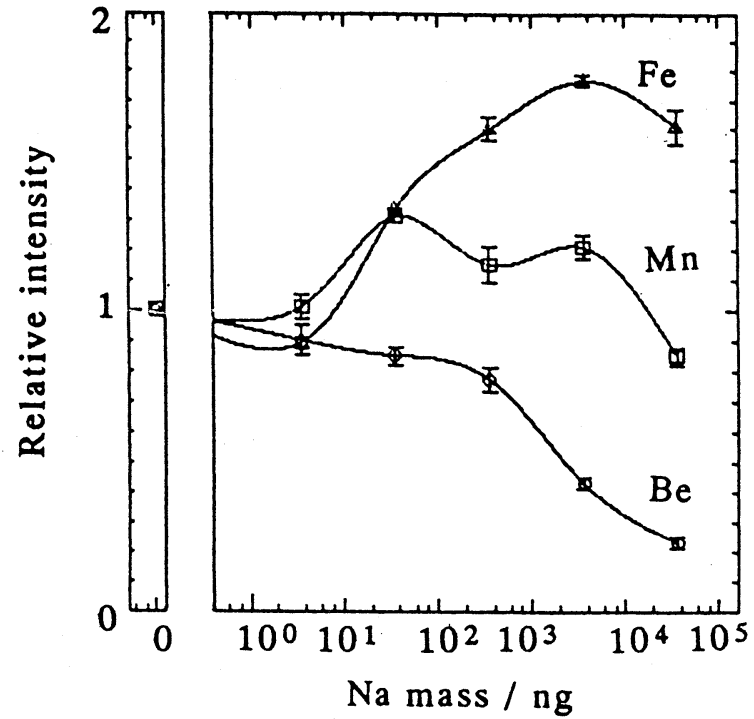

Fig. 7 Effect of easily ionizable element (EIE), Na.

(a), $\mathrm{Zn}, \mathrm{Cu}(10 \mathrm{ng})$ and $\mathrm{Cr}(9.5 \mathrm{ng})$; (b), In, $\mathrm{Pb}$ (100 $\mathrm{ng})$ and $\mathrm{Cd}(10 \mathrm{ng})$; (c), $\mathrm{Fe}$ (100 ng), and Be, $\mathrm{Mn}$ (10 ng).
8. The first peaks appearing around $1.8 \mathrm{sec}$ or at low temperatures are confirmed as those produced from the matrices by measuring the background emissions at wavelengths ca. $0.1 \mathrm{~nm}$ apart from the analytical lines. Using the second emission peaks which appear around $3.7 \mathrm{sec}$, simultaneous direct determinations of multilelements are feasible. The operating conditions and the analytical results obtained with standard addition are listed in Table 6 and 7, respectively. The plasma operating conditions are different from those employed for the solution analyses because of the difference in the stabilizing conditions of the plasma. The precisions were within $15-40 \%$ in terms of relative standard deviation for the measurements repeated at least 5 times. As seen from Table 7 , most of relative errors are within $30 \%$. The found values for $\mathrm{Zn}, \mathrm{Pb}$ and $\mathrm{Cr}$ are in good agreement with the certified ones. The causes of the errors are complicated in conjunction with matrix effect, analyte loss on the charring step, interelement effects, particle size distribution and so on. Particularly, the larger errors for $\mathrm{Fe}$ and $\mathrm{Mn}$ are probably attributable to their higher concentrations, beyond the calibration linear range. In order to overcome this problem, the determinations of high concentration elements have to be carried separately under different conditions, using other analytical lines of weaker intensity.

\section{Conclusions}

In this paper, it is demonstrated that a radio frequency atomization and excitation source (RFAES) is capable of simultaneous direct determinations of multielements including $\mathrm{Cl}$ in solid samples.

Table 6 Operating conditions of Ta cup-RFAES for solid sample

$\begin{array}{ll}\text { r.f. power } & 500 \mathrm{~W} \\ \text { He pressure } & 5.3 \mathrm{kPa} \\ \text { He flow rate } & 1.0 \mathrm{lmin}^{-1} \\ \text { observation height } & 0 \leqq \mathrm{~h} \leqq 25 \mu \mathrm{m} \\ \text { sample volume } & 10 \mu l \\ \text { lid temperature } & \mathrm{ca} .2050^{\circ} \mathrm{C} \\ \text { drying } & 120^{\circ} \mathrm{C}, 3 \mathrm{~min} \\ \text { charring } & 600^{\circ} \mathrm{C}, 60 \mathrm{~S}\end{array}$

Table 7 Direct determinations of NIST SRM1571 Orchard Leaves

\begin{tabular}{ccc}
\hline Element & Found/ppm & $\begin{array}{c}\text { Certificate/reference } \\
\text { value/ppm }\end{array}$ \\
\hline $\mathrm{Zn}$ & $28 \pm 4$ & $25 \pm 3$ \\
$\mathrm{Cr}$ & $3.1 \pm 0.7$ & $(2.3)$ \\
$\mathrm{Pb}$ & $53 \pm 5$ & $45 \pm 3$ \\
$\mathrm{Fe}$ & $225 \pm 17$ & $300 \pm 20$ \\
$\mathrm{Cu}$ & $8 \pm 1$ & $12 \pm 1$ \\
$\mathrm{Mn}$ & $140 \pm 31$ & $91 \pm 4$ \\
$\mathrm{Cl}$ & $621 \pm 99$ & $(700)$ \\
\hline
\end{tabular}




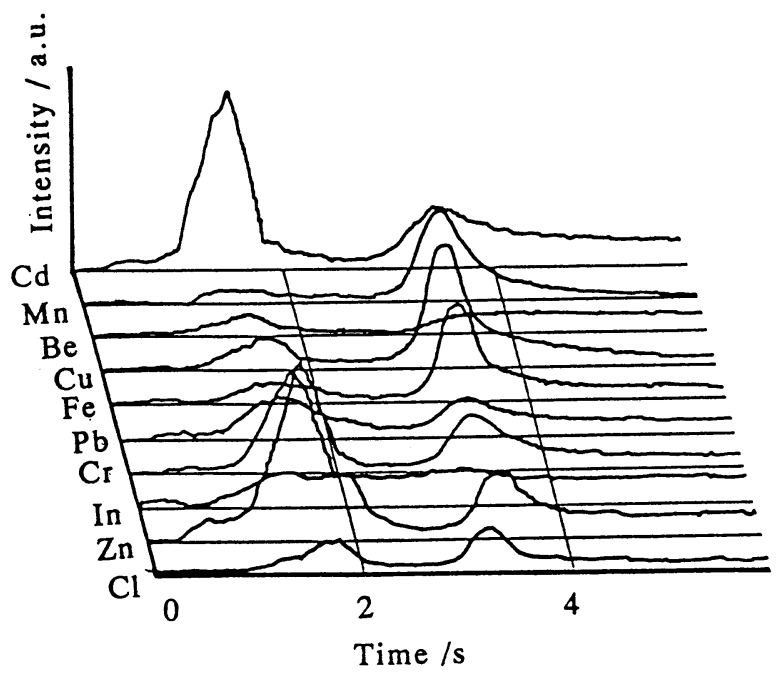

Fig. 8 Typical emission peak profiles obtained for NIST SRM 1571 Orchard Leaves, using the hollow lid.

Although it is revealed that the source developed has some problems, particularly from a viewpoint of precision, it may be emphasized that the merits of this source described in this paper are very useful in practical analyses such as biological and clinical fields, where direct rapid determinations are desirable.

Acknowledgments. The authors thank Mr. S. Takahashi and Mr. K. Tachibana for elaborate manufac- turing of the atomization/excitation source, and $\mathrm{Mr}$. T. Watanabe and Mr. T. Imura for skillful machining of ceramics.

\section{References}

1) K. Kitagawa and T. Katoh: J. Anal. At. Spectrom. 7, 539 (1992).

2) J. Marshall, J. Franks, I. Abel, and C. Tye: J. Anal. At. Spectrom. 6, 145 (1991).

3) Y. Iida Y, A. Tsuge, Y. Uwamino, H. Morikawa, and T. Ishizuka: J. Anal. At. Spectrom. 6, 541 (1991).

4) L. Halicz, I. B. Brenner, and O. Yoffe: J. Anal. At. Spectrom. 8, 475 (1993).

5) M. L. F. Sanchez, B. Fairman, and A. Sanz-Medal: J. Anal. At. Spectrom. 6, 397 (1991).

6) V. Karanassios, M. Abdullah, and G. Horlick: Spectrochim. Acta 45B, 119 (1990).

7) H. Falk, E. Hoffmann, and Ch. Ludke: Prog. Anal. Spectrosc. 11, 417 (1988).

8) K. E. A. Ohlsson, R. E. Sturgeon, S. N. Willie, and V. T. Luong: J. Anal. At. Spectrom. 8, 41 (1993).

9) A. N. Ali, K. C. Ng, and J. D. Winefordner: J. Anal. At. Spectrom. 6, 211 (1991).

10) R. W. Dabeka: Anal. Chem. 64, 2419 (1992).

11) T. T. Gorsuch: Analyst 84, 135 (1959).

12) G. F. R. Gilchrist, P. M. Celliers, H. Yang, C. Yu, and D. C. Liang: J. Anal. At. Spectrom. 8, 80 (1993).

13) T. B. Massalski, I. L. Murray, L. H. Bennettand H. Baker ed.: Binary Alloy Phase Diagrams, Am. Soc. for Metal, Washington D. C. (1986). 